\title{
Editorials
}

\section{To a New Editor-in-Chief}

\author{
"Little do such men know the toil, the pains, \\ The daily, nightly racking of the brains, \\ To range the thoughts, the matter to digest, \\ To cull fit phrases, and reject the rest" \\ Charles Churchill (1731 1764)
}

\section{Dear Editor-in-Chief,}

Congratulations on your appointment. Since Andrew Cudworth's untimely death we have tried to keep the journal moving and the noise you heard was not Concorde over Düsseldorf, but rather our combined sighs of relief that our interim responsibility has ended.

We are sure that editing Diabetologia can be enjouyable despite the times we have been apoplectic with tardy reviewers, angry with ourselves as manuscripts arrive faster than we are able to consider and despatch them, and despite the ever-growing disgruntlement of rejected authors.

No member of the European Association should remain in doubt of the magnitude of the task you have accepted. Diabetologia receives more than four hundred submitted manuscripts each year. Each manuscript generates three referees' reports and all have to be assessed, decided upon, and ranked in priority by the Editor-inChief. Diplomatic letters must be written to authors of rejected manuscripts, and to referees. Longer and more forceful letters will be needed for authors who seem incapable of presenting their scripts in Diabetologia style, while your tact will be necessary to indicate to authors that the discussion section of their beloved manuscript could really be reduced to two pages from the twelve that were submitted.

We have confidence that you will be equal to the task and wish you well.

There is one area which causes us major concern and so we write not just to you, but to the whole membership of the Association. We have noted in recent years an increase in the species homo-iracundia. Members of this species are simple to identify. The milder version enquires "what has happened to my manuscript?" Next up the scale is the "why did it take so long to reach a decision?" and finally there is the reproachful response from the author of a rejected manuscript. Be warned -- such reproaches are rarely mild since the author likely to reproach mildly is usually the one who accepts his fate gracefully. No, regrettably these reproaches are usually vitriolic and abusive. Either your chosen reviewers are incompetent or you have cerebral atrophy for choosing them. As to your inability to perceive the fundamental truths of the manuscript - to say nothing of your decision standing between the author and a Nobel Prize - then you will surely receive suggestions which cast doubt on your conception in wedlock.

Alas we cannot ascribe such behaviour to youthful enthusiasm since it is often the most senior author. Does he not realise that you are but the vehicle for the expression of the referees' opinions. That no matter how gargantuan his reputation, when three reviewers advise you to reject the manuscript no amount of bosom friendship will sway you from this course. Our experience confirms our view that referees' reports must always be anonymous. Any suggestion to the contrary is based on the assumption that all men and women (including authors of manuscripts) are reasonable people. We suggest that this is not always the case and to reveal the source of your referees' reports could entail that referee in endless, abusive, demeaning correspondence with an author.

So we write not only to you, Editor-in-Chief, but to authors, referees and all members of the Association. Referees must accept responsibility for thoughtful and prompt reports. Contributors must accept that decisions may go against them - not on a whim but on sound, reasonable advice. And all members of the Association must accept their responsibility to support you at all times in a difficult job.

We have confidence in you and wish you well. We wish you the perfect world of prompt referees' reports and difficult decisions accepted with grace.

Yours sincerely, Malcolm Nattrass, Robert Tattersall and George Alberti 